\title{
Importowanie mapy zasadniczej do modelu BIM
}

\author{
Andrzej Szymon Borkowski \\ Katedra Gospodarki Przestrzennej i Nauk o Środowisku Przyrodniczym, \\ Wydziat Geodezji i Kartografii, Politechnika Warszawska,e-mail: andrzej.borkowski@pw.edu.pl
}

Streszczenie: Technologia BIM staje się coraz bardziej popularna w procesie projektowania budynków i budowli. Większość modeli powstaje na mapach do celów projektowych przekazywanych projektantom przez geodetów. Jednak projektowane zmiany, w tym wprowadzenie Kodeksu Urbanistyczno-Budowlanego (KUB), mają dopuścić możliwość projektowania na mapie zasadniczej. W ramach likwidacji barier przy wykonywaniu prac geodezyjnych w określonych przypadkach dozwolone ma być projektowanie na mapach zasadniczych. W artykule przedstawiono możliwość zaimportowania mapy wektorowej wykonanej w technologii CAD do modelu BIM. Prawidłowo zaimportowany podkład geodezyjny jest podstawą do dalszego projektowania w technologii BIM.

Słowa kluczowe: technologia BIM; import; mapa zasadnicza.

\section{Wprowadzenie}

Technologia BIM staje się standardem w wielu krajach na całym świecie. Od prawie 10 lat pracują w niej kraje skandynawskie, Stany Zjednoczone czy Kanada. Coraz więcej projektów BIM pojawia w krajach rozwijających się m.in. na bliskim i dalekim wschodzie. Również w Polsce, sektor komercyjny wprowadza technologię BIM, niezależnie już od dłuższego czasu, szczególnie duże firmy [1]. BIM pozwala na szybkie i efektywne projektowanie oraz tworzenie wielu wariantów [2]. Jedną z aplikacji opartych na technologii BIM jest niezwykle popularny na całym świecie Autodesk Revit. Revit umożliwia pracę z danymi CAD oraz GIS, które są niezbędne przy projektowaniu inwestycji punktowych czy liniowych [3]. Mapy do celów projektowych oraz mapy zasadnicze to najczęściej wykorzystywane dane przez projektantów. Ich implementacja często bywa skomplikowana i wymaga odpowiedniej precyzji.

\section{Mapa zasadnicza}

Mapa zasadnicza to podstawowe opracowanie geodezyjno-kartograficzne. Odgrywa bardzo ważną rolę w prowadzeniu dokumentacji geodezyjnej dla całego kraju. Pojęcie mapy zasadniczej, jej przeznaczenia i funkcji określone jest w ustawie Prawo geodezyjne i kartograficzne [4]. W przepisach mapa zasadnicza definiowana jest jako opracowanie wielkoskalowe, które zawiera aktualne informacje o przestrzennym rozmieszczeniu obiektów ogólno-geograficznych oraz elementach ewidencji gruntów, budynków, a także nadziemnych, naziemnych i podziemnych sieci uzbrojenia terenu. Mapa zasadnicza stanowi podstawową bazę dla wszystkich opracowań kartograficznych i obejmuje swoim zasięgiem terytorium całego kraju [5]. Dotychczas niezaktualizowana mapa zasadnicza nie mogła stanowić podstawy do opracowywania projektów budynków czy sieci. Jednak projektowane zmiany, w tym wprowadzenie Kodeksu Urbanistyczno-Budowlanego (KUB), umożliwi 
w pewnych przypadkach projektowanie na mapie zasadniczej. W zdecydowanej większości powiatów mapę zasadniczą można pozyskać w formie wektorowej (CAD). Dzięki temu można ją importować do oprogramowania CAD, GIS lub BIM [6]. Choć należy zaznaczyć, że analogowe mapy zasadnicze również można wczytywać do modeli BIM, lecz nie będą one tak dokładne jak ich wektorowe odpowiedniki. Również praca z obiektami wektorowymi jest zdecydowanie łatwiejsza.

\section{Import danych CAD do modelu BIM}

W celu realizacji niniejszego artykułu pozyskano mapę zasadniczą części gminy Żabia Wola położonej w województwie mazowieckim (Rys. 1). Przed importem mapy zasadniczej do programu opartego na technologii BIM przygotowano odpowiednio plik CAD. Ustawiono jednostki rysunku i zmieniono skalę wstawienia na metry, co umożliwia ustalenie skali wstawianej mapy podczas importu (Rys. 2).

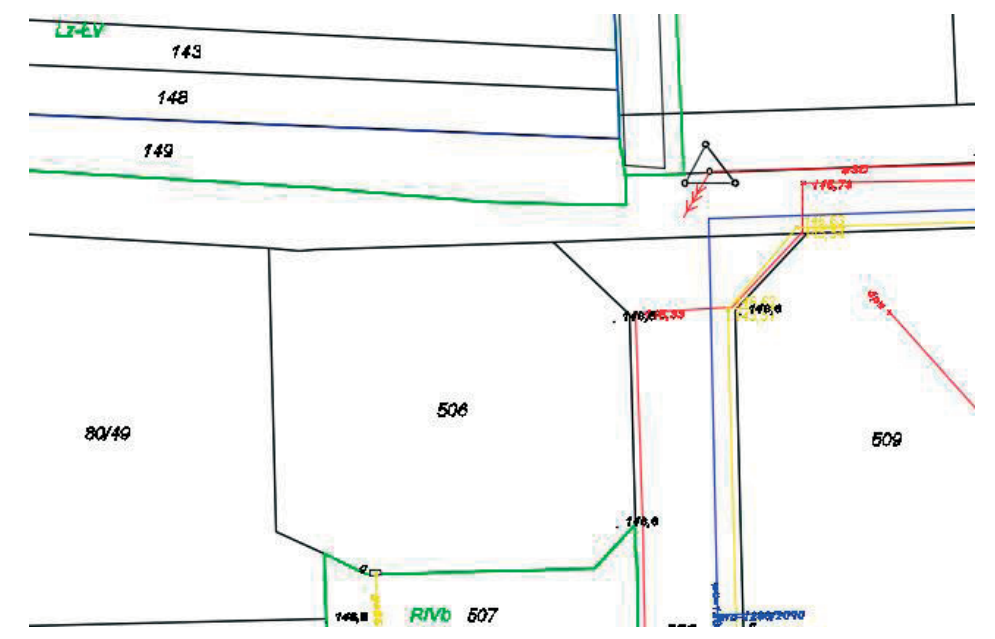

Rys. 1. Fragment wektorowej mapy zasadniczej

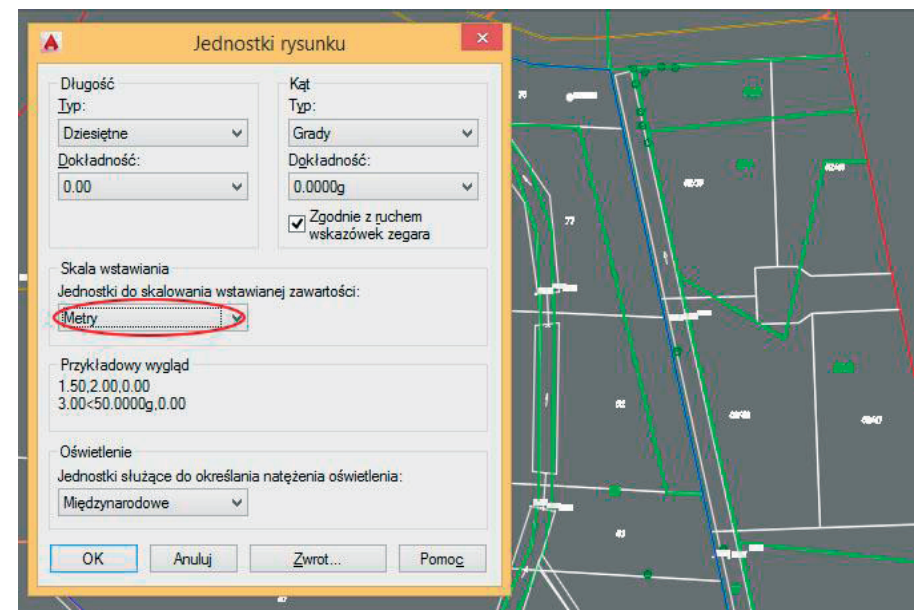

Rys. 2. Ustalenie skali wstawienia w aplikacji AutoCAD 
W aplikacji Revit wybrano szablon do projektowania architektury i zagospodarowania terenu, a następnie ustawiono jednostki projektu (Rys. 3). Wybór szablonu projektu jest niezwykle istotny. Wpływa on bowiem na metody wyświetlania obiektów fizycznych $\mathrm{i}$ analitycznych. Podobnie jest w przypadku wyboru dyscypliny projektu. Wybierając pomiędzy architekturą, konstrukcjami czy instalacjami istnieje możliwość zmiany wyświetlania grafik, materiałów czy tekstur poszczególnych obiektów [7].

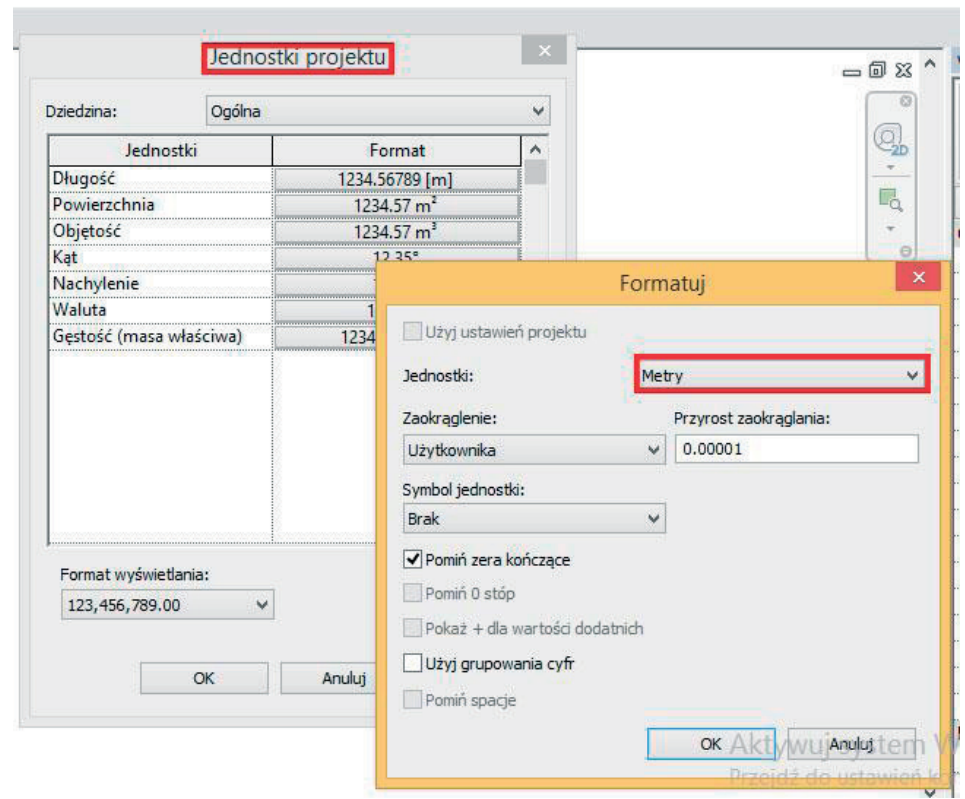

Rys. 3. Ustalenie jednostek projektu w aplikacji Revit

Następnie określono lokalizację położenia projektu (Rys. 4). Lokalizacja jest bardzo ważna ze względu na analizy promieniowania słonecznego i oświetlenia naturalnego.

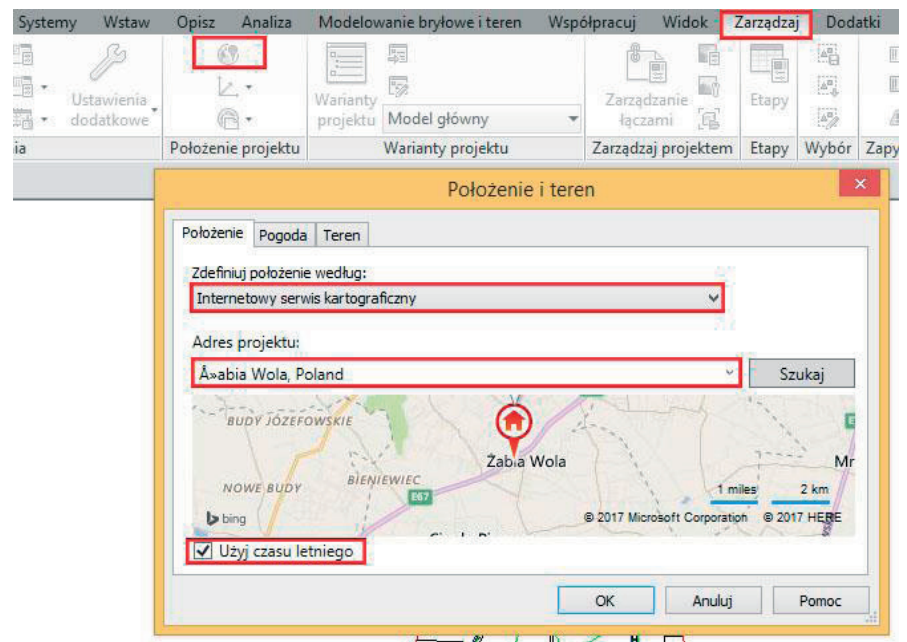

Rys. 4. Ustalenie lokalizacji projektu 
W przypadku lokalizacji do wyboru są dwa systemy lokalizacji: internetowy serwis kartograficzny (WMS) oraz domyślna lista miast. Pierwszy system wymaga połączenia z Internetem, natomiast drugi działa offline. Przed wyborem odpowiedniej lokalizacji należy również sprawdzić czy kraj, w którym sporządzany jest projekt, stosuje czas letni (na terenach państw należących do UE stosuje się czas letni).

Następnie dokonano importu mapy zasadniczej na poziomie terenu (Rys. 5). Teren ze względu na swoje cechy, w tym wyświetlanie elementów topograficznych jest w tym przypadku najlepszym wyborem. Jeśli podkład zawiera informacje o odniesieniu względem poziomu morza, wystąpi potrzeba ustawienia zakresu wyświetlania głównego górnego poziomu na nieograniczony, zaś linię cięcia modelu można ustawić ponad najwyższą rzędną odczytaną z podkładu. Pozwoli to na uniknięcie niekontrolowanego przycięcia modelu terenu. Innym wyjściem jest zmiana rzędnej modelu na najniższą rzędną odczytaną z mapy zasadniczej.
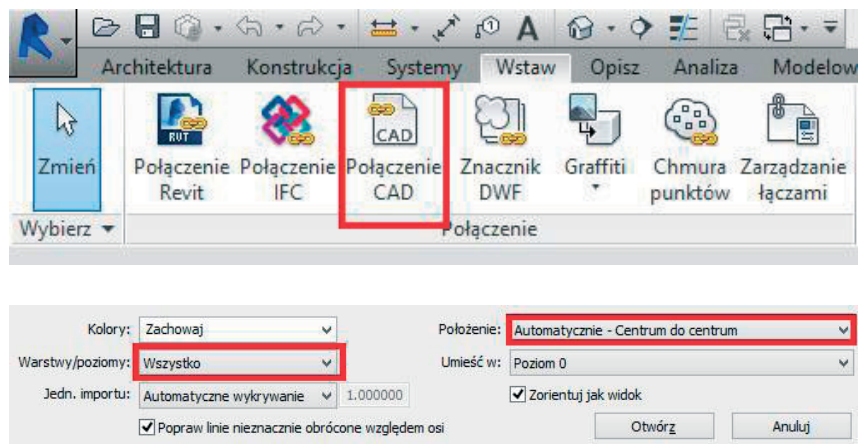

Rys. 5. Opcje importu mapy zasadniczej

Po imporcie podkład ustawiono zgodnie ze współrzędnymi odczytanymi z mapy zasadniczej. Warto oprócz tego ustawić punkt bazowy projektu oraz jeden punkt pomiarowy, do którego projektant będzie mógł na każdym etapie się odnieść (Rys. 6).
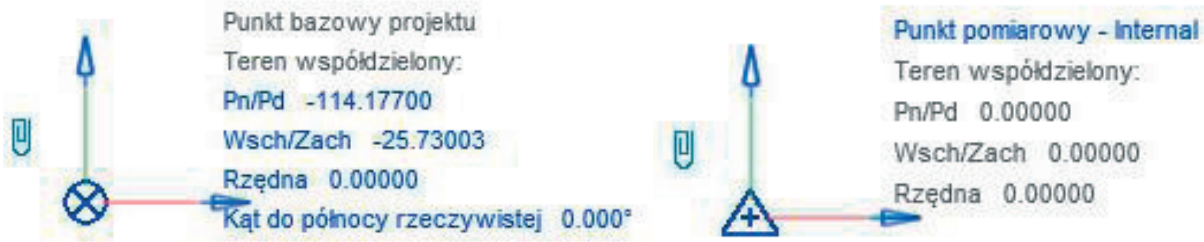

Rys. 6. Punkt bazowy projektu i punkt pomiarowy

\section{Wykorzystanie mapy zasadniczej w modelu BIM}

Technologia BIM umożliwia automatyczne tworzenie trójwymiarowego modelu terenu. Teren można modelować ręcznie, wprowadzając rzędne i położenia punktów lub automatycznie importując pliki z pomiarami geodezyjnymi. Trzecim sposobem jest wykorzystanie pliku DWG, który zawiera rzędne rozmieszczone na odpowiednich wysokościach, tworząc warstwice. 
Revit umożliwia wprowadzanie na mapie zasadniczej etykiet warstwic, granic nieruchomości czy elementów zagospodarowanie terenu. Przed rozpoczęciem modelowania budynku czy inwestycji o charakterze liniowym warto zablokować podkład oraz wymodelowany teren. W ten sposób unika się niepożądanych przesunięć elementów modelu.

W trakcie pracy mogą pojawić się wątpliwości czy przez różnice w pracy programów BIM i CAD, można otworzyć stworzony projekt ponownie w pliku DWG. W tym celu należy pamiętać, że podczas eksportu warto zwrócić uwagę na opcje ustawień jednostek DWG, podstawy układu współrzędnych oraz zapisu łączy jako zewnętrznych odniesień.
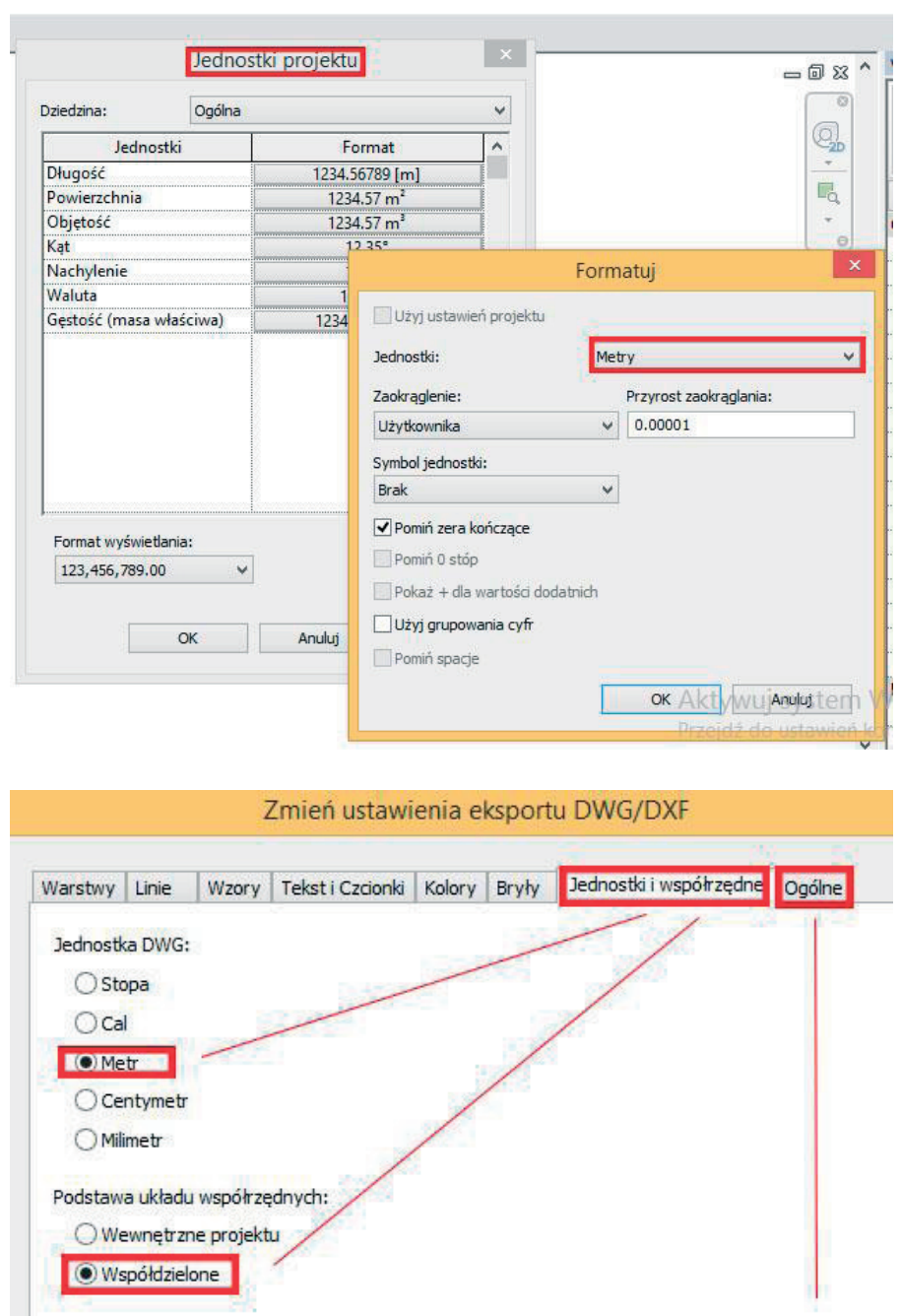

Domyślne opcie eksportowania:

$$
\text { Eksportuj widoki na arkuszach i łącza jako zewnętrzne odniesienia }
$$

Eksportowanie do formatu pliku:
Format AutoCAD 2013

Rys. 7. Opcje eksportu do pliku DWG 
Prawidłowo przygotowany model BIM z mapą zasadniczą przedstawia Rys. 8.

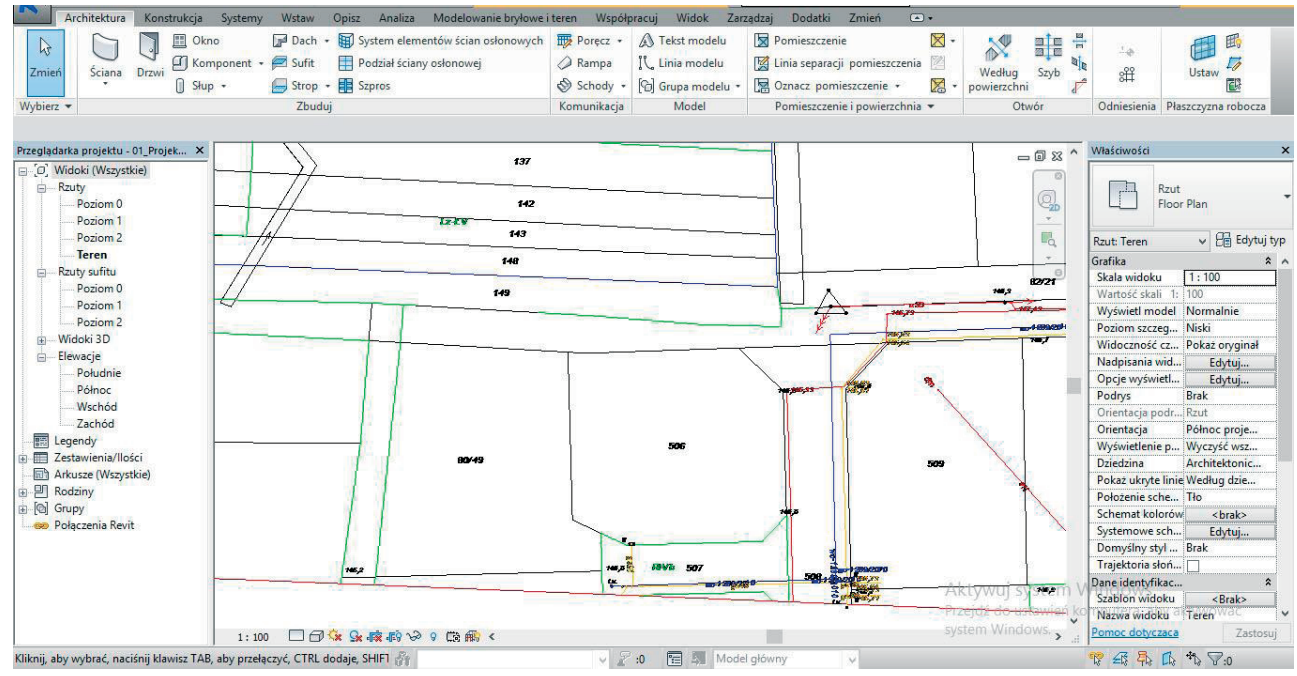

Rys. 8. Mapa zasadnicza w modelu BIM

\section{Podsumowanie}

Wykorzystywanie plików CAD w technologii BIM stanowi duże ułatwienie dla użytkowników programów opartych na BIM. Import mapy zasadniczej jest niezwykle istotny w przypadku dalszych etapów projektowania. Błędnie zaimportowane dane CAD czy GIS będą generować kolejne błędy, a sam projekt być może trzeba będzie tworzyć od początku. Technologia BIM stanowi nową perspektywę w projektowaniu. Zalety i szanse płynące z jej zastosowania, zdecydowanie przeważają nad wadami i wyzwaniami stojącymi przed projektantami.

\section{Literatura:}

1. Walczak Z., Szymczak-Graczyk A., Walczak N. BIM jako narzędzie przyszłości w projektowaniu i rewitalizacji obiektów budowlanych. Przegląd Budowlany 1 (2017) 20-26.

2. Węgierek P., Borkowski A. Sz. Revit Architecture. Podstawy Projektowania. ELPRO Ośrodek Doskonalenia Zawodowego Sp. z o.o., Lublin, 2016.

3. Adach K. Spojrzenie na BIM firmy Autodesk. Materiały Budowlane 9 (2013) 70-71.

4. Ustawa z dnia 17 maja 1989 r. Prawo geodezyjne i kartograficzne. Dz.U. 1989 nr 30 poz. 163.

5. Bielecka E., Izdebski W. Od danych do informacji - teoretyczne i praktyczne aspekty funkcjonowania mapy zasadniczej. 1-12.

http://www.izdebski.edu.pl/kategorie/Publikacje/Izdebski_Bielecka_2014_01.pdf [dostęp z dnia 6.07.2017].

6. Nalepka M., Mrozek R. Zalety i wady technologii BIM. Builder 6 (2017) 118-123.

7. Kołun P., Tomczak A., Turbakiewicz J. Autodesk Revit. Podstawowe funkcje programu. http://bim.put.poznan.pl/skrypt/Skrypt_szkoleniowy-AutodeskRevitpodstawowe_funkcje_programu.pdf [dostęp z dnia 11.06.2017]. 


\title{
Importing the basic map to the BIM model
}

\section{Andrzej Szymon Borkowski}

Department of Spatial Planning and Environmental Sciences, Faculty of Geodesy and Cartography, Warsaw University of Technology, e-mail: andrzej.borkowski@pw.edu.pl

\begin{abstract}
BIM technology becomes more and more popular in the process of design of buildings and construction. Most models are created on maps for design purposes sent to designers by surveyors. However, the proposed changes, including the introduction of the Urban and Building Code, are intended to allow to design on the basic map. In some cases it will be possible to design buildings on the basic maps. The paper presents the possibility of importing a vector map made in CAD technology into the BIM model. Properly imported underlay is the basis for further design in BIM technology.
\end{abstract}

Keywords: BIM technology; import; basic map. 